\title{
Global Managers
}

\section{An Analysis of the Impact of Cultural Intelligence on Job Satisfaction and Performance}

Barakat, Livia L.; Lorenz, Melanie P.; Ramsey, Jase R.; Cretoiu, Sherban L.

Document Version

Accepted author manuscript

Published in:

International Journal of Emerging Markets

DOI:

10.1108/IJoEM-01-2014-0011

Publication date:

2016

License

Unspecified

Citation for published version (APA):

Barakat, L. L., Lorenz, M. P., Ramsey, J. R., \& Cretoiu, S. L. (2016). Global Managers: An Analysis of the Impact of Cultural Intelligence on Job Satisfaction and Performance. International Journal of Emerging Markets, 10(4), 781-800. https://doi.org/10.1108/IJoEM-01-2014-0011

Link to publication in CBS Research Portal

\section{General rights}

Copyright and moral rights for the publications made accessible in the public portal are retained by the authors and/or other copyright owners and it is a condition of accessing publications that users recognise and abide by the legal requirements associated with these rights.

\section{Take down policy}

If you believe that this document breaches copyright please contact us (research.lib@cbs.dk) providing details, and we will remove access to the work immediately and investigate your claim. 


\title{
Global Managers: An Analysis of the Impact of Cultural Intelligence on Job Satisfaction and Performance
}

\author{
Livia Barakat, Melanie P. Lorenz, Jase R. Ramsey, and Sherban L. Cretoiu
}

Journal article (Post print version)

CITE: Global Managers: An Analysis of the Impact of Cultural Intelligence on Job Satisfaction and Performance. / Barakat, Livia L.; Lorenz, Melanie P.; Ramsey, Jase R.; Cretoiu, Sherban L. In: International Journal of Emerging Markets, Vol. 10, No. 4, 2016, p. 781-800.

This article is (5) Emerald Group Publishing and permission has been granted for this version to appear here: http://research.cbs.dk/en/publications/global-managers1788a89a2-4c94-4c2e-bl1065e98f9bab78).html.

Emerald does not grant permission for this article to be further copied/distributed or hosted elsewhere without the express permission from Emerald Group Publishing Limited.

Uploaded to Research@CBS: May २०17 


\section{Introduction}

Managers who can effectively work with peers from different cultures are becoming increasingly valuable in assisting firms to integrate into the global market (Zoogah and Abbey, 2010, Lenartowicz and Johnson, 2007). Global managers are business, country, and/or functional managers who help organizations achieve global-scale efficiency while at the same time national level responsiveness and cross-market learning (Bartlett and Ghoshal, 1992). Global managers are individuals that can understand and balance the dynamics of distinct cultural environments, appraise the differences, and behave appropriately in unfamiliar settings (Cappellen and Janssens, 2005).

While international business (IB) researchers have been focusing on global managers as subjects for years, there still exists an opportunity to explain what influences their performance. In the challenging global business environment, cultural intelligence (CQ) and job satisfaction may be fundamental mechanisms in understanding how global managers perform. Specifically, cultural intelligence, defined as "the capability of an individual to function effectively in situations characterized by cultural diversity" (Ang and Van Dyne, 2008: 3) may help global managers perform better in cross-cultural environments due to a potential increase in job satisfaction. We propose that global managers that are high in CQ will be more satisfied with their jobs. Consistent with the organizational behavior literature, individuals that are more satisfied outperform those that are not. Since the performance of global managers is of particular relevance to organizations, a link (i.e., job satisfaction) from CQ to job performance is relevant. This paper seeks to address the need to better understand the relationship between crosscultural skills and job performance within a global business context (Caligiuri and Tarique, 2012). CQ may represent a valuable cross-cultural skill leading to higher performance. While 
the CQ construct has increased in popularity since its introduction by Earley and Ang (2003), studies often either focus on CQ's immediate antecedents or outcomes. The aim of this study is to investigate the mediation effect of job satisfaction on the CQ-job performance relationship.

By doing so, we make three primary contributions to the IB literature. First, we introduce job satisfaction as a possible outcome variable of CQ. Thus, this work is the first empirical study to test the effect of CQ on the job satisfaction of global managers. Second, although the job satisfaction - job performance relationship is recurrently discussed in the organizational behavior literature (Judge et al., 2001), it is not often explicitly associated with global managers that are working in cross-cultural settings. Finally, we posit that job satisfaction mediates the relationship between CQ and job performance. A survey with global managers from multinational firms operating in Brazil was conducted in order to test our hypotheses.

Insert Figure 1 about here

\section{Literature review}

In the following section, the nature of cultural intelligence is reviewed in order to elucidate the proposed relationship of global managers' cross-cultural capabilities (i.e., CQ), job satisfaction, and job performance. Following this review of CQ, a brief review of job satisfaction is considered as to the extent that it applies to CQ and job performance.

\section{Cultural Intelligence}

CQ is a relatively recent yet well-researched construct in the IB literature that has been theorized as a learning capability for global managers (Dunning and Lundan, 2009). CQ was originally construed in order to understand what influences one's ability to successfully adapt to new cultural contexts (Earley and Ang, 2003). While CQ is related to personality traits, it also explains variance in cross-cultural competencies beyond stable individual differences (Eisenberg 
et al., 2013). Finally, CQ has been proposed as a key element of successful managerial interactions in international markets (Zakak and Douvas, 1999, Alon and Higgins, 2005) because it is positively related to outcomes such as cultural adaption (Templer et al., 2006, Ward et al., 2011), adjustment (Lee and Sukoco, 2010, Chen et al., 2014, Moon, 2010, Ramalu et al., 2012, Lin et al., 2012, Wu and Ang, 2011, Huff et al., 2014), leadership effectiveness (Rockstuhl et al., 2011), intercultural negotiation effectiveness (Imai and Gelfand, 2010), market and product innovation (Elenkov and Manev, 2009), team performance (Moon, 2013), marketing adaptation and export performance (Magnusson et al., 2013), as well as individual performance (e.g., Chen et al., 2011).

Stemming from Sternberg \& Detterman's (1986) multiple intelligence framework, Alon \& Higgins (2005) classify CQ as one component of overall intelligence rather than the more established components of quantitative intelligence (IQ) and emotional intelligence (EQ). This is in line with Van Dyne et al. (2012) who describe CQ as complementary to other forms of intelligences such as general mental ability, emotional intelligence, social intelligence, and practical intelligence. Neither cognitive intelligence nor emotional intelligence include the understanding of cross-cultural settings (Rockstuhl et al., 2011), nor is it limited to problemsolving ability in academic settings (Sternberg and Detterman, 1986). Accordingly, CQ is a malleable competence (Earley and Ang, 2003, Eisenberg et al., 2013), which can be increased and furthered through exposure to different cultures (Triandis, 2006, Crowne, 2013) and active engagement in intercultural experience such as study abroad and international assignments (Dunning and Lundan, 2009).

CQ has four dimensions: meta-cognition, cognition, motivation, and behavior. Metacognition, cognition, and motivation reflect mental capabilities. The behavior-based CQ refers to 
the action domain and includes verbal and nonverbal capabilities (Earley and Ang, 2003). The four components of CQ are described next.

Meta-cognition refers to the higher-order mental processes necessary to analyze, control, and understand knowledge (Ng et al., 2012). It is described as a person's conscious cultural awareness and information processing capacity involving cross-cultural encounters (Ang and Van Dyne, 2008). Individuals high in meta-cognitive capabilities are aware and reflective of their own cultural assumptions and other's cultural preferences. They also self-regulate, develop new heuristics, and adjust cultural knowledge and mental models during interactions (Van Dyne et al., 2012).

Cognition represents an individual's knowledge structure and encompasses the explicit knowledge of norms, values, and practices of respective countries and cultures. These cognitional competencies are acquired through international experience (e.g., work assignments, non-work assignments, exchanges, and travel), and education ( $\mathrm{Ng}$ et al., 2012). Individuals high in cognitive CQ have knowledge of legal, economic, and value systems. They also notice cultural differences and are able to increase accuracy of expectations and predictions in crosscultural interactions (Earley and Ang, 2003, Van Dyne et al., 2012).

Both of these mental capabilities (meta-cognition and cognition) include an individual's self-concept, which is described as a mental representation of one's personality that is formed through experience and cognitive processes (Kihlstrom et al., 1988). Self-efficacy, a more specific component of a person's general self-concept, plays a salient role as it comprises the beliefs of personal competencies to function, perform, and succeed (Bandura, 1997). Knowing oneself and one's preconceptions as well as competencies, in addition to having specific knowledge of social information leads to an enhanced CQ (Earley and Ang, 2003). 
Motivational CQ reflects the desire to initiate, direct, and maintain energy towards learning of and functioning in unfamiliar situations and tasks. The approach to motivation can be based on a person's self-motives or self-concept of enhancement, efficacy, and consistency as described in Erez \& Earley's (1993) cultural self-representation model. Individuals high in motivational CQ tend to be interested in learning about, confident in approaching, and able to cope with new cultural circumstances (Earley and Ang, 2003). Motivational CQ is connected to the mental capabilities of CQ since it is based on the premise that acquiring, processing, and understanding knowledge is dependent on motivation and appropriate channeling (Earley and Ang, 2003).

Finally, behavioral CQ describes an individual's verbal and nonverbal ability to appropriately interact with people from different cultures (Ng et al., 2012). Effective crosscultural behavior is attributed or explained by an individual's self-presentation, which encompasses self-enhancement and impression management (Earley and Ang, 2003). Thus, individuals high in behavioral CQ are aware and considerate of the presentation and impression they make. In particular, they employ and display culturally appropriate behaviors.

These four dimensions are qualitatively different and explain distinctive cross-cultural competencies of managers. Yet they are highly correlated and aggregable to the multidimensional latent construct of overall CQ (Van Dyne et al., 2008). Accordingly, overall CQ encompasses the elements of information processing and awareness capabilities (metacognitive CQ), the knowledge of cultural differences (cognitive CQ), the motivation to bridge those dissimilarities (motivational CQ), and the ability to act upon behavioral cues (behavioral CQ).

\section{Job Satisfaction}


Job satisfaction is defined as the general attitude and positive emotional state reflecting an affective response, reaction, or appraisal of an individual towards his or her work experience conveying the meaning of work success (Locke, 1976, Judge and Hurst, 2008). Several competing approaches have been theoretically and empirically examined in the search for antecedents to job satisfaction (e.g., task characteristics, social information processing, dispositional, and combined). These potential antecedents, although distinct, have all been shown to positively impact job satisfaction (Baker, 2004).

Wu \& Griffin (2012) conducted a longitudinal study of 5,827 British households in order to integrate the dispositional and contextual perspectives in order to better understand job satisfaction. In line with the dispositional perspective of stable personality traits, the authors use core-self-evaluation (CSE) as an antecedent to outcomes such as job satisfaction and performance while accounting for the impact of work experience. CSE is defined as a person's self-concept including the fundamental evaluation of perceived abilities (Judge et al., 1997). People who are high on CSE appraise themselves positively, are more confident about their abilities, and thus more likely to be satisfied with their job (Chang et al., 2012).Yet in contrast to established definitions of CSE as a stable trait, Wu and Griffin (2012) propose that the relationship between CSE and job satisfaction is dynamic. The authors state that "CSE is malleable as the evaluations of our self-concept are intimately tied to our environment" (Judge, 2009). As aforementioned, CQ is based on an individual's self-concept specific to cross-cultural settings or encounters. Accordingly, the antecedents to job satisfaction overlap with some of the tenants of CQ. Both constructs exhibit malleability, dynamism, as well as process and content features (Earley and Ang, 2003). 
Job satisfaction is generally considered a work outcome. Nonetheless, it has also been established as an antecedent to other work results such as withdrawal (Carsten and Spector, 1987, Judge et al., 2000), organizational citizenship behavior (Saari and Judge, 2004), organizational commitment (Yousaf and Sanders, 2012, Cheung et al., 2009) and performance (Wright et al., 2007, Judge et al., 2001).

In a global setting, it's possible that global managers' job satisfaction is related to their cultural adaption or adjustment, which has been theoretically and empirically established as an outcome of CQ (Lee and Sukoco, 2010, Chen et al., 2014, Moon, 2010, Ramalu et al., 2012, Lin et al., 2012, Wu and Ang, 2011, Huff et al., 2014), and as an antecedent to performance.

Similarly, the literature suggests that CQ may be associated with expatriates' satisfaction in the form of comfort or lack of culture shock (Chen et al., 2011). Yet while those constructs may be related, they are distinct and not unequivocally interchangeable. We suggest that the impact of job satisfaction in a global context exceeds comfort, adjustment, and lack of culture shock. For example, it is plausible that a global manager adapts well to a new assignment or cultural environment, yet is not satisfied with the job due to personal or environmental factors.

\section{Hypotheses Development}

\section{Relationship between CQ and Job Satisfaction}

Similarly to CSE, which is manifested as an antecedent of job satisfaction, individuals high in CQ tend to embrace and proactively act upon favorable environments in a cross-cultural setting (Earley and Ang, 2003). For instance, a global manager from a high power distance culture who is able to understand and adapt to a low power distance culture may be more satisfied due to his or her ability to reduce the stress associated with the cross-cultural interaction 
(House et al., 2001). Consequently, constructing and embracing favorable environments is proposed to lead to higher job satisfaction (Best et al., 2005).

In particular, high self-efficacy, a significant component of one's self-concept, is suggested to improve work attitudes such as job satisfaction (Erez and Judge, 2001). In contrast, individuals low in self-efficacy for social interaction in unfamiliar settings will not engage in one's environment (Bandura, 1997) and, may fail to adapt to the new context. These people are inclined to exhibit low CQ (Earley and Ang, 2003), which in turn should negatively affect job satisfaction.

Self-efficacy as an antecedent to job satisfaction and a driver of CQ plays a pivotal role in an international setting. Global managers have to be able to confidently and effectively manage multifaceted cross-cultural interactions in a competitive and complex environment (Bandura, 2002). The effects of self-efficacy, as a tenant of CQ, on job satisfaction are subsequently discussed in light of three aspects: 1) coping with challenges, 2) motivation, and 3) goal setting.

First of all, according to Bandura (1997), individuals high in self-efficacy are willing and motivated to confront and cope with obstacles. They also withdraw less. The propensity to withdraw is frequently discussed as negatively related to job satisfaction (Carsten and Spector, 1987, Judge et al., 2000). This is important in a cross-cultural context because these assignments involve a high risk of failure and often require unexpected adjustment (Earley and Ang, 2003). Global managers' intrinsic motivation may be displayed by their search for international challenges and learning (Cappellen and Janssens, 2005).

Second, global managers high in self-efficacy and CQ are not dependent on instant or constant compensation, but instead accept and understand the possibility of delayed rewards 
(Earley and Ang, 2003). Hence, culturally adept managers are not primarily driven by and exclusively focused on extrinsic rewards.

Finally, individuals high in self-efficacy tend to engage in goal-setting, which leads to positive actions and outcomes (Locke and Latham, 1990). Managers high in CQ proactively search for efficient ways to engage their environment in the pursuit of their goals (Earley and Ang, 2003). Self-concordant objectives are associated with job satisfaction as managers who follow congruent goals are happier with these goals, and lead to increased effort and motivation to achieve them (Erez and Judge, 2001). Intrinsic motivation further tends to be enhanced if the goals are personally important and enjoyable (Judge et al., 2005). Accordingly, individuals pursuing challenging goals as a function of a high CQ are inclined to develop positive attitudes toward their job.

Therefore, we hypothesize:

Hypothesis 1. CQ is positively related to job satisfaction.

See Figure 1 for a pictorial representation of the three hypotheses of this study.

\section{The Relationship between Job Satisfaction and Job Performance}

The relationship between job satisfaction and job performance has been firmly established in the organizational behavior literature. The underlying premise is that favorable attitudes about an object lead to behaviors that foster or support it, while unfavorable attitudes about an object are linked to behaviors that do not support it (Eagly and Chaiken, 1993, Fishbein and Ajzen, 1975). Thus, positive attitudes toward the job (e.g., satisfaction) should be related to positive behaviors (e.g., job performance). Whereas some studies failed to provide significant evidence of the positive association between these constructs, others have shown a moderate or even strong relationship (Judge et al., 2001). Thus, despite being widely studied, further research 
on the topic may help address recurrent critiques of inconsistency and inconclusiveness of results.

It is also worth investigating if this relationship holds when surveying different types of subjects. While the majority of the literature utilized students or domestic employees as subjects (i.e., Rich et al., 2010, Sheridan and Slocum Jr, 1975), to the best of our knowledge this is the first attempt to test the relationship between job satisfaction and job performance of exclusively global managers in an emerging market. This initiative is especially relevant in today's business environment in which increased globalization calls for professionals who are able to manage complex interactions in emerging markets (Bartlett and Ghoshal, 1992).

Therefore, in line with previous scholarship, yet with global managers as subjects in an emerging market, we hypothesize:

Hypothesis 2. Job satisfaction is positively related to job performance.

The Mediating Role of Job Satisfaction on the CQ-Job Performance Relationship

Support for the CQ-job performance relationship can be found in several empirical studies. First, Chen et al. (2011) established a positive correlation between overall CQ and performance in their study of 382 Philippine laborers working in Taiwan's manufacturing industries. We seek to extend their work by focusing on higher-level employees (e.g., managers and above) that have a global aspect to their jobs. Second, Abdul Malek, \& Budhwar (2013) examined expatriates based in multinational corporations in Malaysia and found a positive influence of CQ on performance. However, the authors used a 13-item reduced CQ scale divided into awareness and interaction sub-scales instead of the overall multidimensional construct. Third, Ang et al. (2007) in their study of workers' task performance only found significant evidence of the CQ- performance relationship for the behavioral and meta-cognitive 
components as opposed to the effect of overall CQ. Fourth, Ramalu et al. (2012) investigated the relationship between $\mathrm{CQ}$, cross-cultural adjustment, and job performance of expatriates assigned to Malaysia. Results revealed that CQ is positively related to job performance. Also, interaction and work adjustment partially mediated this relationship. Fifth, Wu and Ang's (2011) analysis of expatriates in Singapore revealed that expatriate supporting practices were positively related to adjustment and performance. Whereas, metacognitive and cognitive CQ negatively moderated the relationship between supporting practices and adjustment, motivational CQ had a positive moderating effect. As many studies of the CQ_-performance relationships have focused on Asian countries, we seek to extend CQ research to the emerging market of Brazil. Finally, Chen, Kirkman, Kim, Farh, \& Tangirala (2010) and Chen et al. (2012) exclusively focused on motivational CQ as an antecedent of performance. In summary, while the aforementioned authors have made significant strides in understanding the $\mathrm{CQ}$ - performance relationship, there is still an opportunity for evidence from upper-level global employees' performance based on the original overall 20-item CQ construct.

According to MacKinnon, Coxe, \& Baraldi (2012), "theories across many substantive disciplines focus on the mediating processes as explanations for how and why an antecedent variable is related to an outcome variable". Thus, underpinned by the assumptions of the CQ construct, we argue that job satisfaction (driven by an individual's self-concept) may explain the how component of the relationship between CQ and job performance. This is based on the notion that job satisfaction is a variable transmitting the effect of CQ to job performance.

CQ theorists propose that CQ is partially driven by an individual's self-concept, which increases the chances and motivation of adaption and appropriate behavior in unknown cultural settings (Earley and Ang, 2003). Furthermore, global managers' job satisfaction is derived from 
positive work experiences and an individual's positive self-concept or CSE. Individuals with high CQ are more motivated, goal-oriented, and possess the appropriate knowledge that enhances job satisfaction. Since job satisfaction has a moderate relationship with job performance (Judge et al., 2001), we suggest that job satisfaction plays a pivotal role in the CQjob performance relationship.

In regard to the arguments provided, we suggest that a third variable, job satisfaction, transmits the effect of the independent variable (CQ) to the dependent variable (job performance). Thus, we posit:

Hypothesis 3. Job satisfaction mediates the relationship between CQ and job performance.

\section{Methods \\ Data Collection and Sample Profile}

In order to test the three hypotheses of this study, a survey was conducted targeting global managers from multinationals operating in Brazil (Brazilian or foreign). Seventy-one multinational companies were selected to participate in the study of which 23 accepted (32\% company response rate). Companies were selected from two different sources: 1) A Ranking of Brazilian Transnationals (Cretoiu et al., 2012); 2) GADEX and GDI, two large groups of Brazilian and foreign multinationals that meet monthly to discuss international HRM issues (GADEX, 2012, GDI, 2012). All participating companies are considered large according to the Brazilian size classification (net revenue greater than US\$140 million) (BNDES, 2012). Thirteen companies were Brazilian controlled and 10 foreign controlled.

Next, we contacted the participant companies' human resources department, who selected professionals in managerial or leadership positions (supervisors, managers, directors and/or 
presidents/CEOs) with global responsibilities to respond to the survey (Adler and Bartholomew, 1992). To be considered having "global responsibilities" individuals must have two or more of the following job characteristics: 1) have at least weekly interaction with other cultures; 2) travel outside of the base country at least twice a year; 3) be an expatriate; and 4) coordinate global activities (e.g., managing foreign teams, controlling foreign affiliates, and managing contacts with foreign clients and suppliers). These criteria were selected based on an exploratory study with seven Brazilian MNCs. We interviewed international HR directors regarding the nature of their companies' global managers' roles and activities (Abdala and Barakat, 2012). Having two of the four job characteristics were enough to be considered a global manager and eligible for the survey (Bartlett and Ghoshal, 1992). Respondents could be working either in the headquarters or in foreign affiliates. Samples within companies ranged from one to 63 individuals per company, averaging 14.4. A total of 364 managers received the questionnaire. Global managers accessed the survey through an online questionnaire provided by the research team. Follow-ups and reminders were sent to the companies over a period of three months. Each company's HR department reinforced the invitation to respond during this period. The final sample consisted of 332 respondents $(91.2 \%$ individual response rate).

The majority of the sample is male $(81.0 \%)$ and Brazilian $(83.7 \%)$. Other nationalities include Germany, Argentina, Canada, Chile, Colombia, El Salvador, France, Japan, Mexico, Netherlands, New Zealand, Paraguay, Peru, Spain, United Kingdom, Uruguay, USA, and Venezuela. The respondent's age ranged from 26 to 64 and averaged 41.5 years old. On average, the global managers in the study have worked for 13.2 years in the companies currently employing them.

\section{Measurement}


In the current study, cultural intelligence constitutes the independent variable, job satisfaction the mediating variable, and job performance the dependent variable. Validated scales were used to measure all of the variables.

To assess cultural intelligence we used the scale developed by Ang, Van Dyne, Koh, Ng, Temper, Tay, \& Chadrasekar (2007). Their scale is a multidimensional construct comprised of 20 items composing the four sub-dimensions of metacognitive, cognitive, motivational, and behavioral CQ. For example, respondents were asked to evaluate statements such as "I adjust my cultural knowledge as I interact with people from a culture that is unfamiliar to me", "I enjoy interacting with people from different cultures", and "I am sure I can deal with the stress of adjusting to a culture that is new to me". Across various studies, the items of the scale show moderate to strong relationships (inter-correlations of $0.46-0.66$ ), reflecting the internal consistency of the measurement (Ang et al., 2007). Further, research demonstrates the value and predictive validity of self-report versions of the scale (Kim and Van Dyne, 2012, Van Dyne et al., 2008, Ward et al., 2009). In the current study, the overall CQ provided high reliability (0.92 Cronbach’s Alpha, 0.93 Composite Reliability).

Job satisfaction was measured using the overall job satisfaction scale by Agho, Price, \& Mueller (1992). The authors designed a one-dimensional construct with six items which correlates positively with employee's perception of performance and supervisor support (Agho et al., 1993, Aryee et al., 1999, Judge et al., 1998). In particular, Brooke et al. (1988) showed that the overall job satisfaction measure was empirically distinct from organizational commitment and job involvement. The scale includes questions about the enthusiasm, enjoyment, and satisfaction with the current work situation and job. For example, respondents were asked to rate the statements "I find real enjoyment in my work" and "I am satisfied with my job for the time 
being”. The items in this sample achieved good reliability ( 0.80 Cronbach's Alpha, 0.86 Composite Reliability).

Job performance was measured with the 5 -item scale created by Pearce and Porter (1986). The items asked managers to recall their last performance evaluation and to report how they were rated. In particular, respondents are asked to assess their overall performance, their ability to get along with others, their ability to get the task done on time, the quality of their performance, and the achievement of work goals. The response format was specifically developed for managers in different organizations to capture the actual perceived performance, regardless of differences in performance appraisal systems, which was critical for this study due to the number of different firms and occupations. This measure has been shown to be highly correlated with supervisors' ratings of performance (Pearce and Porter, 1986). Cronbach's Alpha for this sample was 0.74 and Composite Reliability was 0.81 .

Cultural intelligence was measured with a seven-point Likert type scale in which respondents indicated their level of agreement or disagreement with the statements $(0=$ strongly disagree, $6=$ strongly agree). Job satisfaction and job performance were assessed using a fivepoint Likert type scale $(0=$ strongly disagree to $4=$ strongly agree $)$. All constructs were reliable (CR's > 0.80 (Bagozzi and Yi, 1988) and Cronbach's Alpha > 0.70 (Nunnally and Bernstein, 1978)). Discriminant validity was established since the square root of the average variance extracted by each construct exceeds the correlation between all pairs of substantive constructs (Fornell and Larcker, 1981) (see table 1 for the correlation matrix including AVEs).

English and Portuguese versions of the questionnaire were available. Brazilian native speakers received the Portuguese version of the questionnaire whereas foreigners received the English version. Since English was a job requirement for all the expatriates in the study, using 
the English version on those cases seemed appropriate. The translation process was carried out in two ways: 1) for cultural intelligence we used the Portuguese scale that had been translated and validated by a previous study (Araujo and Nunes, 2012); and 2) for job satisfaction and job performance, the original English scales were translated (and back translated) to Portuguese by an accredited translator. All of the scales were pre-tested with five global managers from a nonparticipating company to verify face validity.

We also controlled for age, gender, and tenure. Tenure and age were measured in years and gender was dummy coded $(1=$ Male, $0=$ Female). Age, tenure, and gender are controls consistently used in CQ research (Ang et al., 2007, Eisenberg et al., 2013). As age and gender are suggested to influence cross-cultural adjustments (Chen et al., 2012), they may influence other attitudinal outcomes such as job satisfaction. Furthermore, we controlled for tenure as previous studies report that tenure facilitates job performance based on the accumulated work experiences (McDaniel et al., 1988).

\section{Statistical Analyses}

We conducted the data analyses using SPSS 20.0. First, we discussed the characteristics of the sample population by providing the descriptive statistics for tenure, gender, and age. Then we examined the bivariate correlations between all the variables. Next, using a standard pathanalytic approach described by Preacher and Hayes (2008), we examined the effects of overall CQ on job performance, both directly and indirectly through job satisfaction.

\section{Common Method Bias}

Because the constructs in our study are attitudes and individual perceptions, we had to rely on single-source and self-report data. Therefore, we recognize that our measurements are subject to common method bias (CMB) (Conway and Lance, 2010, Podsakoff et al., 2003). 
We minimized the likelihood of inflated relationships, a priori, through careful study design and took steps in line with Podsakoff and colleagues (Podsakoff et al., 2003, 2012) in the administration of the data collection. First, we chose a sample population with the ability, education, and cognitive sophistication to understand and comprehend the survey questions (e.g., global managers with regular international contact). Second, we employed different scales and some negatively worded items to decrease the chance of satisficing. Satisficing may occur when respondents choose answers stylistically instead of providing accurate assessments (MacKenzie and Podsakoff, 2012). Third, we selected questions which are personally important for the respondents, abstained from forcing respondents to participate, created a relatively short survey (10-12 minutes), and refrained from complex and ambiguous items to enhance motivation and avoid respondent fatigue. Fourth, in order to reduce social desirability bias and to mitigate social consequences of revealing true judgment, the interviewer was not present during the administration of the survey and respondents were ensured that the results will only be used for research purposes. Fifth, we reversed the causal order of independent and dependent variable items in the survey to reduce selecting answers based on implicit theories about the study outcome and the relationships between the scales. Finally, we guaranteed our respondents that the survey was based on their own personal evaluations to avoid the perception of right or wrong answers (Podsakoff et al., 2003, MacKenzie and Podsakoff, 2012).

Further, post-hoc, we empirically assessed whether any common source effects biased our results. Using SPSS Amos 22 we added a "method factor" to our measurement model (including the constructs of CQ, Satisfaction, and Performance) with all items loading on their latent constructs as well as on the method factor. If the addition of the method factor improved the model fit, CMB is present. Results revealed that the model including the method factor 
provided better fit to the data $\left(\mathrm{X}^{2}(387)=883.879, \mathrm{p}<0.0001 ; \mathrm{CFI}=0.91\right.$; $\left.\mathrm{RMSEA}=0.063\right)$ than the original measurement model $\left(\mathrm{X}^{2}(418)=1279.007, \mathrm{p}<0.001 ; \mathrm{CFI}=0.86 ; \mathrm{RMSEA}=0.079\right)$. Moreover, the differences between the models $\left(\Delta X^{2}(31)=395.13, p<0.001\right)$ was significant thus suggesting the existence of CMB. Although CMB is present, there is evidence that it was not serious enough to threaten our hypotheses testing. First, there was no difference in the significance level of the correlations between the study variables in the tested models. Second, examining the average variance extracted (AVE) revealed that the method factor only accounted for $24 \%$ of the variance in the data; thus our results were below the threshold of $25 \%$ (Williams et al., 1989).

\title{
Results
}

Descriptive statistics, reliabilities and correlations

Table 1 presents descriptive statistics, reliabilities, and correlations for all of the variables. A total of 332 global managers from 23 multinational companies (MNCs) completed the survey.

Consistent with our predictions, overall CQ was positively related to job satisfaction and job performance. Job satisfaction was positively related to job performance.

\author{
Insert Table 1 about here \\ Simple Mediation \\ We estimated the subsequent models to assess the total, direct, and indirect effects of \\ overall CQ on job performance through job satisfaction. The INDIRECT procedure for SPSS \\ was used to derive the coefficients for the following equations (Preacher \& Hayes, 2008). As the \\ SPSS INDIRECT macro is a sophisticated regression instrument and we only rely on one \\ independent variable, one mediation variable, and one dependent variable, it provides a suitable
}


tool for the current analysis. Furthermore, the INDIRECT procedure is a stronger test of our mediation analysis than SEM as it provides the advantage of bootstrapping. Bootstrapping may reveal more accurate mediation results as it samples repeatedly from the data set and estimates the indirect effect in each respective set. Additionally, this procedure does not assume normality of the sampling distribution (Preacher and Hayes, 2004). Finally, MacKinnon et al. (2002) examined the performance of different mediation methods and recommended bootstrapping (which is part of the INDIRECT procedure) because it offers higher power while maintaining adequate control over the Type 1 error rate (Preacher and Hayes, 2008).

Covariates comprised of tenure, age, and gender, which we included simultaneously in addition to the predictor variables.

(1) Job performance $=$ constant $+c($ overall CQ $)+$ covariates + error

(2) Job satisfaction $=$ constant $+a($ overall CQ $)+$ covariates + error

(3) Job performance $=$ constant $+c^{\prime}($ overall CQ $)+b($ job satisfaction $)+$ covariates + error

Coherent with our theoretical argumentation, job performance was superior among those individuals with higher overall CQ (Table 2, Model 2 and path c in Figure 2). Furthermore, based on the results of Table 2 (Model 1, and path a in Figure 2) overall CQ was positively associated with job satisfaction. Individuals with higher CQ experienced higher job satisfaction supporting Hypothesis 1.

Moreover, consistent with our prediction, job satisfaction was positively related to job performance, which confirmed Hypothesis 2 (Table 2, Model 2, and path b in Figure 2). Finally, the direct effect of overall CQ as can be seen in Table 2, Model 3 and path c' in Figure 2 was statistically significant for job performance.

In order to assess the mediation hypothesis (Hypothesis 3) we estimated the indirect effect of overall CQ on job performance. The indirect effects are calculated as the product of the 
OLS regression coefficient estimating job satisfaction based on overall CQ (path a in Figure 2) and job performance based on job satisfaction while controlling for overall CQ (path $\mathrm{b}$ in Figure 2). We utilized a bias-corrected bootstrap-confidence interval (CI) for the product of these paths which provides evidence of significant indirect effects of overall CQ on job performance through job satisfaction if the CI does not include zero. The analysis with 5,000 bootstrap resamples showed a significant positive indirect effect of overall CQ on job performance through job satisfaction (point estimate $=.05,95 \%$ percentile, CI .02 to .09). Hence, Hypothesis 3 received support.

In order to ensure that the causal order between the mediator and the dependent variable was not reversed, we tested job performance as the mediator of the CQ-job satisfaction relationship with the SPSS INDIRECT macro. Results revealed that job performance partially mediates the relationship between CQ and job satisfaction. However, comparing the model results demonstrated that although partial mediation could be established for both mediation models, the overall model with job satisfaction as the mediator $\left(\mathrm{R}^{2}=0.10\right)$ explained significantly higher variance than the overall model with performance as the mediator $\left(\mathrm{R}^{2}=0.05\right)$.

Insert Table 2 about here

\section{Discussion}

\section{Theoretical and Research Implications}

In this study, we examined the effect of global managers' CQ on job performance through job satisfaction. As MNEs continue to increase their reliance on individuals that can perform well in the highly uncertain context of emerging markets, so should academia. Our results demonstrate that the job performance of global managers was higher for those with greater levels of CQ. Individuals who are able to recognize, understand, and adjust to cross- 
cultural differences outperform those that cannot (lower CQ). This study is the first to test this relationship among global managers in Brazil, which increases the generalizability of other studies that have looked at CQ and job performance around the globe.

Yet unlike most empirical studies in the CQ literature, we wanted to look for a third variable that connects CQ and job performance. While the literature and our study support the CQ - job performance direct relationship, we believe that job satisfaction resulting from the positive work experiences and an individual's positive self-concept is able to transmit an additional effect of CQ to job performance. This study represents a first attempt to analyze job attitudes (i.e., job satisfaction) as a mechanism by which overall CQ affects job performance using a mediation approach. Our results show that when a global manager isn't satisfied with his job, then the positive effects of having a high CQ are weaker. Since we found both direct and indirect effects of CQ on job performance, we cannot affirm that job satisfaction is the sole justification for why culturally intelligent global managers tend to perform better. If not a condition, job satisfaction seems to be an important element for global managers to get better results from their cultural interactions. We believe that there exists a large opportunity in the CQ literature to investigate more mediators in the already established direct relationships between CQ and other outcomes.

Our findings suggest that CQ is positively related to job satisfaction after controlling for age, gender, and tenure. As we mentioned in our hypothesis development, high CQ is linked to a positive self-concept and self-efficacy in global managers. This positive self-concept as a prominent tenant of CQ may influence how global managers feel about their work. Hence, global managers that are knowledgeable of and able to understand and adjust to cultural differences might develop a more positive attitude about their job, leading to increased job satisfaction. For 
most individuals, working in a high cultural distance country such as those in the emerging markets, is stressful. When individuals are overly stressed, they are usually less satisfied and perform worse. We believe that this stress can be mitigated by selecting and training individuals high is CQ.

Finally, we used the construct of overall CQ as an antecedent to job satisfaction and job performance. Thanks to the suggestion of one of our anonymous reviewers, we did a post hoc analysis that broke out all four components of CQ. While they were all positively related to job satisfaction and job performance, when we inserted them into the regression analysis, the effect of the cognitive component of CQ turned negative. This finding provides researchers with further support concerning the hazards of breaking out the components of CQ in their studies. It would have been relatively easy to have (incorrectly) concluded that increasing one's cognitive CQ harms job satisfaction and job performance. Therefore, we suggest either using the latent overall CQ measure, or selecting one or two components of the CQ measure.

\section{Implications for Practice}

Global managers in emerging markets are confronting complex challenges navigating and performing in cross-cultural settings. Multinational companies should be aware of the underlying mechanisms driving job satisfaction and performance. This study suggests that international HR managers should select individuals high in CQ, and train those that are not. The 20 -item CQ instrument is readily available and could be implemented into a firm's hiring process. Furthermore, there are current studies being conducted that demonstrate that CQ can be taught. We expect that in the relatively short term, researchers (and consultants) will become more accurate on understanding what techniques work best to train various profiles of individuals. 
Finally, while most MNCs are looking for an increase in performance of their global managers, it is important to note that increasing their job satisfaction in the global context significantly improves the impact of CQ on performance. Practitioners can incentivize individuals to set high goals with regards to interacting with others in emerging markets. They can also motivate them to engage by communicating that the long term rewards of increasing their CQ will be positively related to their job satisfaction and ultimately performance. And lastly, many individuals think that they can't improve their cultural intelligence (possibly due to past literature on IQ). By reinforcing that CQ can be learned, individuals will aspire to cope with the challenges of operating in these complex environments.

\section{Limitations and Future Research}

This study is not without limitations which should be addressed in order to extend the current IB literature on this topic. First, although the majority of our findings are in line with the proposed model, they cannot be interpreted as proof of a causal relationship among the study variables due to the use of cross-sectional data. For example, the organizational behavior literature proposes various models of how job satisfaction is related to job performance. The relationship has been tested in an inverted direction, reciprocal, and included moderators and mediators (i.e., Judge et al., 2001). The proposed causality may be supported by the various studies mentioned in the literature review which established empirically and theoretically that adjustment may be an outcome of CQ (Lee and Sukoco, 2010, Moon, 2010), an antecedent to performance (e.g., Chen et al., 2010), and a mediator of the CQ-performance relationship (Abdul Malek and Budhwar, 2013). As we term job satisfaction as related to the perception of adjustment/adaptation, the causal order and relationship should be similar, supporting job 
satisfaction as the mediator variable. Nonetheless, future research should measure these variables at distinct points of time to determine the order of the cause and effect.

Furthermore, the generalizability of the study may be limited, as the sample was focused on multinational companies operating in Brazil. Although the companies were globally active and many of the respondents were expatriates (hailing from 26 different countries), the setting might have impacted our results. Future studies should extend the breadth of the subjects of analysis to other countries and cultures.

Moreover, the use of self-reports might have created a distortion of results for two reasons. First, in the current sample, means for all variables were relatively high $(.70+$ percentile on the scales), suggesting that most global managers assessed themselves positively in regard to these components. Future research might control for social desirability to account for an accurate self-assessment. Further, Thomas et al., (2008) suggest self-reports might not be adequate to capture CQ and recommend the use of distinct procedures to assess the sub-components instead of an overall CQ measure. Possible procedures include observation, tracing techniques, and knowledge-specific techniques. Second, using self-reports for all of the variables might have resulted in common method bias (Podsakoff et al., 2003). Albeit, a priori, we minimized the common methods effects through careful study design. Further, a post-hoc test revealed that although CMB was present it did not threaten our hypotheses testing. Although present, this potential risk of conflated relationships between variables was limited due to the use of reliable measurement constructs and a sufficient sample size. Nevertheless, future research should incorporate multiple measurement methods that capture other perspectives, such as behavioral observations or reports from managers, subordinates, or co-workers. 
Finally, as pointed out by a reviewer, we could have added personality variables as

controls in order to demonstrate the incremental validity of CQ in predicting job performance.

\section{References}

ABDALA, V. D. \& BARAKAT, L. 2012. O Gestor Global: Um Profissional Dotado de Global Mindset. DOM, 19, 9-19.

ABDUL MALEK, M. \& BUDHWAR, P. 2013. Cultural intelligence as a predictor of expatriate adjustment and performance in Malaysia. Journal of World Business, 48, 222-231.

ADLER, N. J. \& BARTHOLOMEW, S. 1992. Managing globally competent people. Academy of Management Executive, 6, 52-65.

AGHO, A. O., MUELLER, C. W. \& PRICE, J. L. 1993. Determinants of employee job satisfaction: An empirical test of a causal model. Human Relations, 46, 1007-1027.

AGHO, A. O., PRICE, J. L. \& MUELLER, C. W. 1992. Discriminant validity of measures of job satisfaction, positive affectivity and negative affectivity. Journal of Occupational and Organizational Psychology, 65, 185-195.

ALON, I. \& HIGGINS, J. M. 2005. Global leadership success through emotional and cultural intelligences. Business Horizons, 48, 501-512.

ANG, S. \& VAN DYNE, L. 2008. Conceptualization of cultural intelligence: Definition, distinctiveness, and nomological network. Handbook of cultural intelligence: Theory, measurement, and applications, 3-15.

ANG, S., VAN DYNE, L., KOH, C., NG, K. Y., TEMPLER, K. J., TAY, C. \& CHANDRASEKAR, N. A. 2007. Cultural intelligence: Its measurement and effects on cultural judgment and decision making, cultural adaptation and task performance. Management and Organization Review, 3, 335-371.

ARAUJO, B. F. V. B. D. \& NUNES, I. M. Inteligência Cultural, Adaptação Transcultural e Desempenho de Expatriados: um estudo por meio de Equações Estruturais. In: ANPAD, ed. Encontro do ENANPAD, 2012 Rio de Janeiro. ENANPAD, 16.

ARYEE, S., FIELDS, D. \& LUK, V. 1999. A cross-cultural test of a model of the work-family interface. Journal of Management, 25, 491-511.

BAGOZZI, R. P. \& YI, Y. 1988. On the evaluation of structural equation models. Journal of the Academy of Marketing Science, 16, 74-94.

BAKER, W. K. 2004. Antecedents and consequences of job satisfaction: Testing a comprehensive model using integrated methodology. Journal of Applied Business Research, 20, 31-44.

BANDURA, A. 1997. Self-efficacy: The exercise of self-control, Gordonsville, VA, WH Freeman \& Co.

BANDURA, A. 2002. Social cognitive theory in cultural context. Applied Psychology, 51, 269290.

BARTLETT, C. A. \& GHOSHAL, S. 1992. What Is a Global Manager? Harvard Business Review, 70, 124-132.

BEST, R. G., STAPLETON, L. M. \& DOWNEY, R. G. 2005. Core self-evaluations and job burnout: the test of alternative models. Journal of Occupational Health Psychology, 10, 441-451. 
BNDES 2012. Classificação de tamanho de empresas (Company size classification). Banco Nacional do Desenvolvimento (National Bank of Development).

BROOKE, P. P., RUSSELL, D. W. \& PRICE, J. L. 1988. Discriminant validation of measures of job satisfaction, job involvement, and organizational commitment. Journal of Applied Psychology, 73, 139-145.

CALIGIURI, P. \& TARIQUE, I. 2012. Dynamic cross-cultural competencies and global leadership effectiveness. Journal of World Business, 47, 612-622.

CAPPELLEN, T. \& JANSSENS, M. 2005. Career paths of global managers: Towards future research. Journal of World Business, 40, 348-360.

CARSTEN, J. M. \& SPECTOR, P. E. 1987. Unemployment, job satisfaction, and employee turnover: A meta-analytic test of the Muchinsky model. Journal of Applied Psychology, 72, 374-381.

CHANG, C.-H. D., FERRIS, D. L., JOHNSON, R. E., ROSEN, C. C. \& TAN, J. A. 2012. Core Self-Evaluations A Review and Evaluation of the Literature. Journal of Management, 38, 81-128.

CHEN, A. S.-Y., LIN, Y.-C. \& SAWANGPATTANAKUL, A. 2011. The relationship between cultural intelligence and performance with the mediating effect of culture shock: A case from Philippine laborers in Taiwan. International Journal of Intercultural Relations, 35, 246-258.

CHEN, A. S.-Y., WU, I.-H. \& BIAN, M.-D. 2014. The moderating effects of active and agreeable conflict management styles on cultural intelligence and cross-cultural adjustment. International Journal of Cross Cultural Management, 1-19.

CHEN, G., KIRKMAN, B. L., KIM, K., FARH, C. I. \& TANGIRALA, S. 2010. When does cross-cultural motivation enhance expatriate effectiveness? A multilevel investigation of the moderating roles of subsidiary support and cultural distance. Academy of Management Journal, 53, 1110-1130.

CHEN, X.-P., LIU, D. \& PORTNOY, R. 2012. A multilevel investigation of motivational cultural intelligence, organizational diversity climate, and cultural sales: evidence from US real estate firms. Journal of Applied Psychology, 97, 93-106.

CHEUNG, M. F., WU, W.-P., CHAN, A. K. \& WONG, M. M. 2009. Supervisor-subordinate guanxi and employee work outcomes: The mediating role of job satisfaction. Journal of Business Ethics, 88, 77-89.

CONWAY, J. M. \& LANCE, C. E. 2010. What reviewers should expect from authors regarding common method bias in organizational research. Journal of Business and Psychology, 25, 325-334.

CRETOIU, S. L., BARAKAT, L., NOGUEIRA, V. S. \& DINIZ, L. D. M. 2012. 2012 Ranking of Brazilian Transnationals: The Benefits of Internationalization. Nova Lima: Fundacao Dom Cabral.

CROWNE, K. A. 2013. Cultural exposure, emotional intelligence, and cultural intelligence: An exploratory study. International Journal of Cross Cultural Management, 13, 5-22.

DUNNING, J. H. \& LUNDAN, S. M. 2009. The Internationalization of Corporate R\&D: A Review of the Evidence and Some Policy Implications for Home Countries. Review of Policy Research, 26, 13-33.

EAGLY, A. H. \& CHAIKEN, S. 1993. The psychology of attitudes, Harcourt Brace Jovanovich College Publishers. 
EARLEY, P. C. \& ANG, S. A. 2003. Cultural intelligence: Individual interactions across cultures, Stanford business books.

EISENBERG, J., LEE, H.-J., BRÜCK, F., BRENNER, B., CLAES, M.-T., MIRONSKI, J. \& BELL, R. 2013. Can Business Schools Make Students Culturally Competent? Effects of Cross-Cultural Management Courses on Cultural Intelligence. Academy of Management Learning \& Education, 12, 603-621.

ELENKOV, D. S. \& MANEV, I. M. 2009. Senior expatriate leadership's effects on innovation and the role of cultural intelligence. Journal of World Business, 44, 357-369.

EREZ, A. \& JUDGE, T. A. 2001. Relationship of core self-evaluations to goal setting, motivation, and performance. Journal of Applied Psychology, 86, 1270-1279.

EREZ, M. \& EARLEY, P. C. 1993. Culture, self-identity, and work, Oxford University Press New York.

FISHBEIN, M. \& AJZEN, I. 1975. Belief, Attitude, Intention and Behavior, Massachusetts, Addison-Wesley.

FORNELL, C. \& LARCKER, D. F. 1981. Evaluating structural equation models with unobservable variables and measurement error. Journal of Marketing Research, 39-50.

GADEX. 2012. Grupo de Administração de Expatriados (Expatriates Management Group) [Online]. São Paulo: http://www.gadex.com.br/. [Accessed 01/12 2013].

GDI. 2012. Grupo de Designados Internacionais (International Assigned Group) [Online]. Rio de Janeiro: www.gdirh.com.br. [Accessed 01/12 2013].

HOUSE, R., JAVIDAN, M. \& DORFMAN, P. 2001. Project GLOBE: An Introduction. Applied Psychology: An International Review, 50, 489-505.

HUFF, K. C., SONG, P. \& GRESCH, E. B. 2014. Cultural intelligence, personality, and crosscultural adjustment: A study of expatriates in Japan. International Journal of Intercultural Relations, 38, 151-157.

IMAI, L. \& GELFAND, M. J. 2010. The culturally intelligent negotiator: The impact of cultural intelligence (CQ) on negotiation sequences and outcomes. Organizational Behavior and Human Decision Processes, 112, 83-98.

JUDGE, T. A. 2009. Core self-evaluations and work success. Current Directions in Psychological Science, 18, 58-62.

JUDGE, T. A., BONO, J. E., EREZ, A. \& LOCKE, E. A. 2005. Core self-evaluations and job and life satisfaction: The role of self-concordance and goal attainment. Journal of Applied Psychology, 90, 257-268.

JUDGE, T. A., BONO, J. E. \& LOCKE, E. A. 2000. Personality and job satisfaction: The mediating role of job characteristics. Journal of Applied Psychology, 85, 237-249.

JUDGE, T. A., BONO, J. E., THORESEN, C. J. \& PATTON, G. K. 2001. The Job SatisfactionJob Performance Relationship: A Qualitative and Quantitative Review. Psychological Bulletin, 127, 376-407.

JUDGE, T. A. \& HURST, C. 2008. How the rich (and happy) get richer (and happier): Relationship of core self-evaluations to trajectories in attaining work success. Journal of Applied Psychology, 93, 849-863.

JUDGE, T. A., LOCKE, E. A. \& DURHAM, C. C. 1997. The dispositional causes of job satisfaction: A core-evaluations approach. Research in Organizational Behavior, 19, 151188. 
JUDGE, T. A., LOCKE, E. A., DURHAM, C. C. \& KLUGER, A. N. 1998. Dispositional effects on job and life satisfaction: The role of core evaluations. Journal of Applied Psychology, 83, 17-34.

KIHLSTROM, J. F., ALBRIGHT, J. S., KLEIN, S. B., CANTOR, N., CHEW, B. R. \& NIEDENTHAL, P. M. 1988. Information processing and the study of the self. Advances in Experimental Social Psychology, 21, 145-178.

KIM, Y. J. \& VAN DYNE, L. 2012. Cultural intelligence and international leadership potential: The importance of contact for members of the majority. Applied Psychology, 61, 272294.

LEE, L.-Y. \& SUKOCO, B. M. 2010. The effects of cultural intelligence on expatriate performance: The moderating effects of international experience. The International Journal of Human Resource Management, 21, 963-981.

LENARTOWICZ, T. \& JOHNSON, J. P. 2007. Staffing managerial positions in emerging markets: a cultural perspective. International Journal of Emerging Markets, 2, 207-214.

LIN, Y.-C., CHEN, A. S.-Y.\& SONG, Y.-C. 2012. Does your intelligence help to survive in a foreign jungle? The effects of cultural intelligence and emotional intelligence on crosscultural adjustment. International Journal of Intercultural Relations, 36, 541-552.

LOCKE, E. A. 1976. The nature and causes of job satisfaction. In: DUNNETT, M. D. (ed.) Handbook of industrial and organizational psychology. Chicago, United States: Rand McNally.

LOCKE, E. A. \& LATHAM, G. P. 1990. Work motivation and satisfaction: Light at the end of the tunnel. Psychological Science, 1, 240-246.

MACKENZIE, S. B. \& PODSAKOFF, P. M. 2012. Common method bias in marketing: causes, mechanisms, and procedural remedies. Journal of Retailing, 88, 542-555.

MACKINNON, D. P., COXE, S. \& BARALDI, A. N. 2012. Guidelines for the investigation of mediating variables in business research. Journal of Business and Psychology, 27, 1-14.

MACKINNON, D. P., LOCKWOOD, C. M., HOFFMAN, J. M., WEST, S. G. \& SHEETS, V. 2002. A comparison of methods to test mediation and other intervening variable effects. Psychological Methods, 7, 83-104.

MAGNUSSON, P., WESTJOHN, S. A., SEMENOV, A. V., RANDRIANASOLO, A. A. \& ZDRAVKOVIC, S. 2013. The role of cultural intelligence in marketing adaptation and export performance. Journal of Marketing Research, 21, 44-61.

MCDANIEL, M. A., SCHMIDT, F. L. \& HUNTER, J. E. 1988. Job experience correlates of job performance. Journal of Applied Psychology, 73, 327-330.

MOON, T. 2010. Organizational Cultural Intelligence: Dynamic Capability Perspective. Group \& Organization Management, 35, 456-493.

MOON, T. 2013. The effects of cultural intelligence on performance in multicultural teams. Journal of Applied Social Psychology, 43, 2414-2425.

NG, K.-Y., VAN DYNE, L., ANG, S. \& RYAN, A. 2012. Cultural intelligence: A review, reflections, and recommendations for future research. In: RYAN, A. M., LEONG, F. T. L. \& OSWALD, F. L. (eds.) Conducting Multinational Research: Applying Organizational Psychology in the Workplace Washington, DC: American Psychological Association.

NUNNALLY, J. C. \& BERNSTEIN, I. 1978. Psychometry theory. New York: McGraw-Hill.

PEARCE, J. L. \& PORTER, L. W. 1986. Employee responses to formal performance appraisal feedback. Journal of Applied Psychology, 71, 211-218. 
PODSAKOFF, P. M., MACKENZIE, S. B., LEE, J.-Y. \& PODSAKOFF, N. P. 2003. Common method biases in behavioral research: A critical review of the literature and recommended remedies. Journal of Applied psychology, 88, 879-903.

PREACHER, K. J. \& HAYES, A. F. 2004. SPSS and SAS procedures for estimating indirect effects in simple mediation models. Behavior Research Methods, Instruments, \& Computers, 36, 717-731.

PREACHER, K. J. \& HAYES, A. F. 2008. Asymptotic and resampling strategies for assessing and comparing indirect effects in multiple mediator models. Behavior Research Methods, 40, 879-891.

RAMALU, S., ROSE, R. C., ULI, J. \& KUMAR, N. 2012. Cultural intelligence and expatriate performance in global assignment: The mediating role of adjustment. International Journal of Business and Society, 13, 19-32.

RICH, B. L., LEPINE, J. A. \& CRAWFORD, E. R. 2010. Job Engagement: Antecedents and Effects on Job Performance Academy of Management Journal, 53, 617-635.

ROCKSTUHL, T., SEILER, S., ANG, S., VAN DYNE, L. \& ANNEN, H. 2011. Beyond General Intelligence (IQ) and Emotional Intelligence (EQ): The Role of Cultural Intelligence (CQ) on Cross-Border Leadership Effectiveness in a Globalized World. Journal of Social Issues, 67, 825-840.

SAARI, L. M. \& JUDGE, T. A. 2004. Employee attitudes and job satisfaction. Human Resource Management, 43, 395-407.

SHERIDAN, J. E. \& SLOCUM JR, J. W. 1975. The Direction of the Causal Relationship Between Job Satisfaction and Work Performance. Organizational Behavior \& Human Performance, 14, 159-172.

STERNBERG, R. J. \& DETTERMAN, D. K. 1986. What is intelligence?: Contemporary viewpoints on its nature and definition, Ablex Publishing Corporation.

TEMPLER, K. J., TAY, C. \& CHANDRASEKAR, N. A. 2006. Motivational cultural intelligence, realistic job preview, realistic living conditions preview, and cross-cultural adjustment. Group \& Organization Management, 31, 154-173.

THOMAS, D. C., ELRON, E., STAHL, G., EKELUND, B. Z., RAVLIN, E. C., CERDIN, J.-L., POELMANS, S., BRISLIN, R., PEKERTI, A. \& AYCAN, Z. 2008. Cultural Intelligence Domain and Assessment. International Journal of Cross Cultural Management, 8, 123143.

TRIANDIS, H. C. 2006. Cultural Intelligence in Organizations. Group \& Organization Management, 31, 20-26.

VAN DYNE, L., ANG, S. \& KOH, C. 2008. Development and Validation of the CQS. Handbook of cultural intelligence. Theory, measurement and applications, Sharpe, New York, 16-38.

VAN DYNE, L., ANG, S., NG, K. Y., ROCKSTUHL, T., TAN, M. L. \& KOH, C. 2012. SubDimensions of the Four Factor Model of Cultural Intelligence: Expanding the Conceptualization and Measurement of Cultural Intelligence. Social and Personality Psychology Compass, 6, 295-313.

WARD, C., FISCHER, R., LAM, F. S. Z. \& HALL, L. 2009. The convergent, discriminant, and incremental validity of scores on a self-report measure of cultural intelligence. Educational and Psychological Measurement, 69, 85-105.

WARD, C., WILSON, J. \& FISCHER, R. 2011. Assessing the predictive validity of cultural intelligence over time. Personality and Individual Differences, 51, 138-142. 
WILLIAMS, L. J., COTE, J. A. \& BUCKLEY, M. R. 1989. Lack of method variance in selfreported affect and perceptions at work: reality or artifact? Journal of Applied Psychology, 74, 462-468.

WRIGHT, T. A., CROPANZANO, R. \& BONETT, D. G. 2007. The Moderating Role of Employee Positive Well Being on the Relation Between Job Satisfaction and Job Performance. Journal of Occupational Health Psychology, 12, 93-104.

WU, C.-H. \& GRIFFIN, M. A. 2012. Longitudinal relationships between core self-evaluations and job satisfaction. Journal of Applied Psychology, 97, 331-342.

WU, P.-C. \& ANG, S. H. 2011. The impact of expatriate supporting practices and cultural intelligence on cross-cultural adjustment and performance of expatriates in Singapore. The International Journal of Human Resource Management, 22, 2683-2702.

YOUSAF, A. \& SANDERS, K. 2012. The Role of Job Satisfaction and Self-Efficacy as Mediating Mechanisms in the Employability and Affective Organizational Commitment Relationship: A Case From a Pakistani University. Thunderbird International Business Review, 54, 907-919.

ZAKAK, A. \& DOUVAS, S. 1999. Insurance globalization requires cultural intelligence. Journal of Commerce, 6A.

ZOOGAH, D. B. \& ABBEY, A. 2010. Cross-cultural experience, strategic motivation and employer hiring preference: An exploratory study in an emerging economy. International Journal of Cross Cultural Management, 10, 321-343. 
Tables

Table 1. Means, Standard Deviations, and Correlations between all Variables

\begin{tabular}{lrrrrrrrr}
\hline \multicolumn{1}{c}{ Variable } & Mean & Std Dev & 1 & 2 & 3 & 4 & 5 & 6 \\
\hline 1. Tenure & 13.22 & 9.66 & & & & & & \\
2. Age & 41.48 & 7.87 & $0.52^{* * *}$ & & & & & \\
3. Gender & 0.82 & 0.38 & $0.12^{*}$ & $0.11^{*}$ & & & & \\
4. CQ & 5.66 & 0.61 & -0.01 & -0.04 & 0.07 & $(0.62)$ & & \\
5. Job Satisfaction & 4.01 & 0.53 & 0.05 & -0.03 & 0.01 & $0.22^{* * *}$ & $(0.72)$ & \\
6. Job Performance & 4.40 & 0.43 & -0.00 & $-0.11^{*}$ & -0.01 & $0.30^{* * *}$ & $0.36^{* * *}$ & $(0.68)$ \\
\hline
\end{tabular}

Notes: $\mathrm{N}=332,{ }^{*} \mathrm{p}<.05,{ }^{* *} \mathrm{p}<.01, * * * \mathrm{p}<.001$, Gender is coded $0=$ female and $1=$ male

Square roots of the AVEs for the substantive constructs are reported on the diagonal.

Table 2. Ordinary Least Squares Regression Coefficients

\begin{tabular}{|c|c|c|c|}
\hline \multirow[b]{2}{*}{ Outcome $\rightarrow$} & \multirow{2}{*}{$\begin{array}{c}\text { Job Satisfaction } \\
\text { Model } 1\end{array}$} & \multicolumn{2}{|c|}{ Job Performance } \\
\hline & & Model 2 & Model 3 \\
\hline Constant & $3.09 * * *(.32)$ & $2.76 * * *(.27)$ & $3.51 * * *(.25)$ \\
\hline Overall CQ & $.18 * * *(.05)$ & $.16^{* * *}(.04)$ & $.21 * * *(.04)$ \\
\hline Tenure & $.01(.00)$ & $.00(.00)$ & $.00(.00)$ \\
\hline Age & $-.01(.00)$ & $-.01 *(.00)$ & $-.01 * *(.00)$ \\
\hline Gender & $-.02(.08)$ & $-.03(.06)$ & $-.03(.06)$ \\
\hline Job Satisfaction & & $.24 * * *(.04)$ & \\
\hline$R^{2}$ & .05 & .19 & .10 \\
\hline
\end{tabular}

Notes: $\mathrm{N}=332,{ }^{*} \mathrm{p}<.05,{ }^{* *} \mathrm{p}<.01, * * * \mathrm{p}<.001$, Gender is coded $0=$ female and $1=$ male 


\section{Figures}

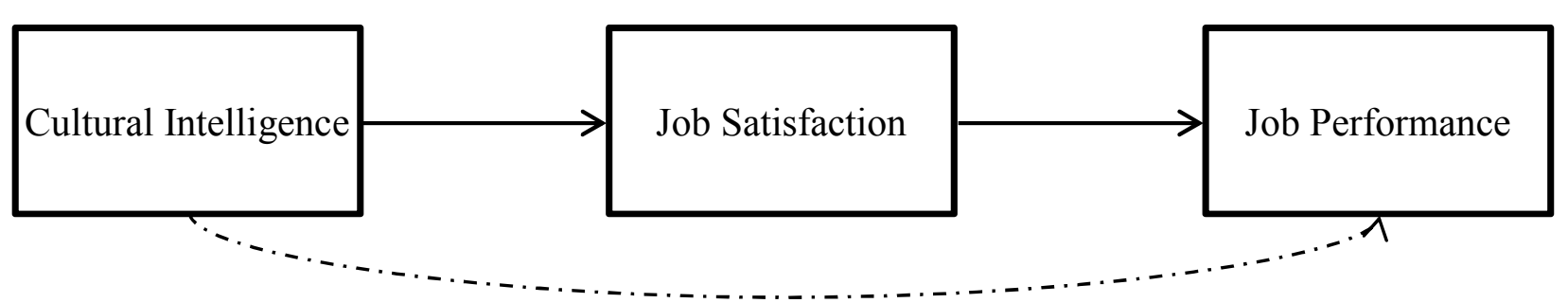

Figure 1. Conceptual Model linking CQ to Job Performance

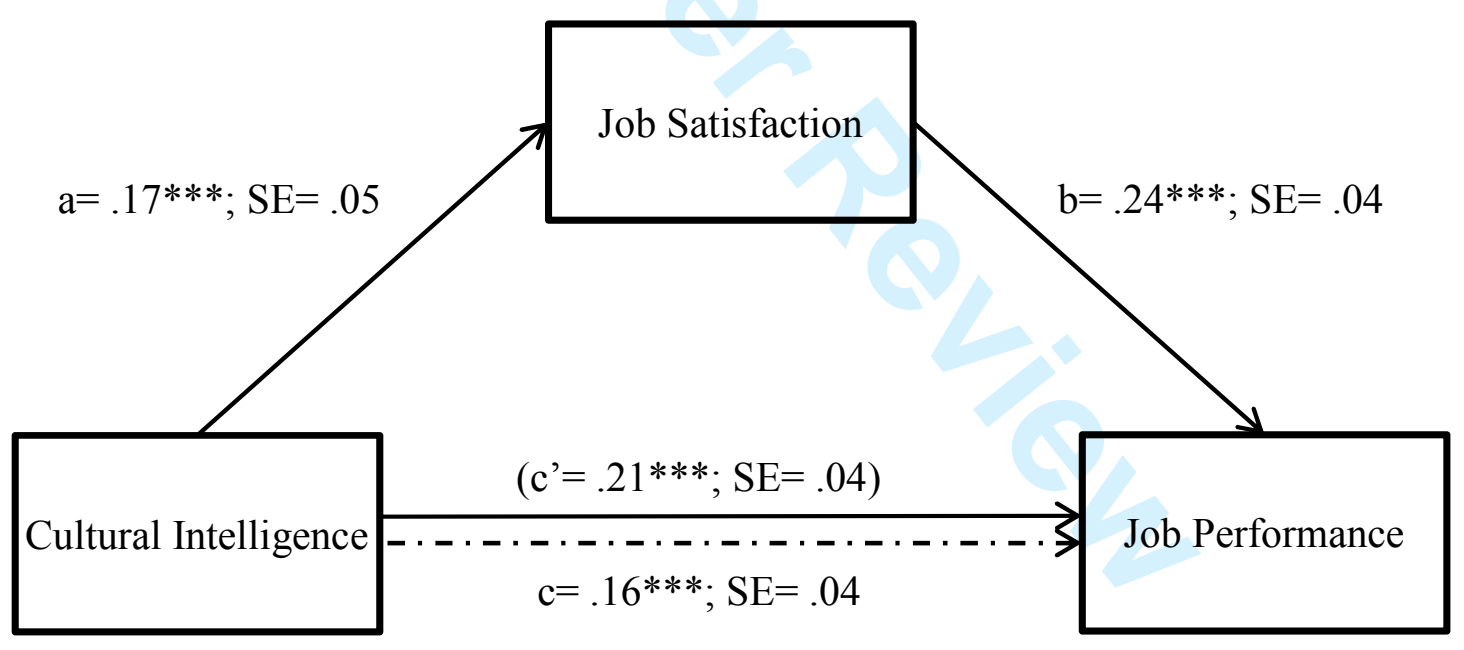

Figure 2. Path coefficients for simple mediation analysis on job performance $(\mathrm{N}=332)$

Note: Dotted line denotes the effect of overall CQ on job performance when job satisfaction is not included as a mediator. A, b, c and c' are unstandardized OLS regression coefficients. Age, tenure, and gender were included as covariates but are not represented here.

Notes: $\mathrm{N}=332, * \mathrm{p}<.05, * * \mathrm{p}<.01, * * * \mathrm{p}<.001$ 